Int. J. Dev. Biol. 57: 525-533 (2013)

doi: $10.1387 / \mathrm{ijdb} .130208 \mathrm{dw}$

\title{
From jellyfish to biosensors: the use of fluorescent proteins in plants
}

\author{
UTE VOß ${ }^{1}$, ANTOINE LARRIEU ${ }^{1,2}$ and DARREN M. WELLS ${ }^{*, 1}$ \\ ${ }^{1}$ Centre for Plant Integrative Biology, School of Biosciences, University of Nottingham, UK and \\ ${ }^{2}$ Laboratoire de Reproduction et Développement des Plantes, CNRS, INRA, ENS Lyon, UCBL, Université de Lyon, Lyon, France.
}

\begin{abstract}
The milestone discovery of green fluorescent protein (GFP) from the jellyfish Aequorea victoria, its optimisation for efficient use in plantae, and subsequent improvements in techniques for fluorescent detection and quantification have changed plant molecular biology research dramatically. Using fluorescent protein tags allows the temporal and spatial monitoring of dynamic expression patterns at tissue, cellular and subcellular scales. Genetically-encoded fluorescence has become the basis for applications such as cell-type specific transcriptomics, monitoring cell fate and identity during development of individual organs or embryos, and visualising protein-protein interactions in vivo. In this article, we will give an overview of currently available fluorescent proteins, their applications in plant research, the techniques used to analyse them and, using the recent development of an auxin sensor as an example, discuss the design principles and prospects for the next generation of fluorescent plant biosensors.
\end{abstract}

KEY WORDS: fluorescent protein, transgenic plant, biosensor, DII-VENUS, confocal microscopy

\section{Introduction}

Genetically encoded fluorescent proteins (FPs) represent powerful tools for biological research. This article will review the development of FPs for use in plants together with current applications and recent advances in microscopy techniques. Fluorescent reporter design and techniques for fluorescence quantification will be discussed using the recently-developed DII-VENUS auxin biosensor as an example, together with perspectives for future developments.

\section{Genetically-encoded fluorescent reporters: from a slow start to a bright future}

Three years after the production of the first transgenic plants, the first light-emitting plant was generated (Ow et al., 1986), an event considered newsworthy enough to be reported by both TIME magazine and The Today Show (Lemonick 1986; Bazell and Palmer 1986). This transgenic tobacco plant contained the gene for the enzyme luciferase from the firefly Photinus pyralis and when provided with the appropriate substrate, luciferin, emitted enough light for an image to be captured on photographic film following a lengthy (24h) exposure (Fig. 1A). Reporters based on FPs rather than enzyme-mediated bioluminescence were not available until the cloning of the gene for green fluorescent protein (GFP) six years later (Prasher et al., 1992). GFP had been identified in the jellyfish Aequorea victoria thirty years earlier (Shimomura et al., 1962). A. victoria emits green light whereas the bioluminescent protein isolated from its photogenic tissues, aequorin, emits blue light in the presence of calcium ions in vitro. Co-localised to the same tissues, GFP was shown to be excited by aequorin bioluminescence, emitting the green light which gives the characteristic hue to $A$. victoria luminescence (Morise et al., 1974).

The cloning of the GFPgene provided researchers with a marker that could be expressed in vivo, detected in real time and which required no substrates or cofactors (Millwood et al., 2008). The first report of successful expression of GFP in the model organisms Escherichia coli and Caenorhabditis elegans was published two years after its cloning (Chalfie et al., 1994). The next three years saw GFP transiently expressed in plants: in Arabidopsis thaliana tissues and in protoplasts of Citrus sinensis and Zea mays (Sheen et al., 1995; Niedz etal., 1995; Chiu et al., 1996). However, attempts to produce stable transformants in Arabidopsis resulted in plants with no detectable fluorescence signal (Sheen et al., 1995). It was

Abbreviations used in this paper: FRET, fluorescence resonance energy transfer; FLIM, fluorescence lifetime imaging; FRAP, fluorescence recovery after photobleaching; GFP, green fluorescent protein.

\footnotetext{
*Address correspondence to: Darren M. Wells. CPIB, School of Biosciences, University of Nottingham, Sutton Bonington Campus, LE12 5RD, UK. e-mail: darren.wells@nottingham.ac.uk
}

Final, author-corrected PDF published online: 16 September 2013.

ISSN: Online 1696-3547, Print 0214-6282 

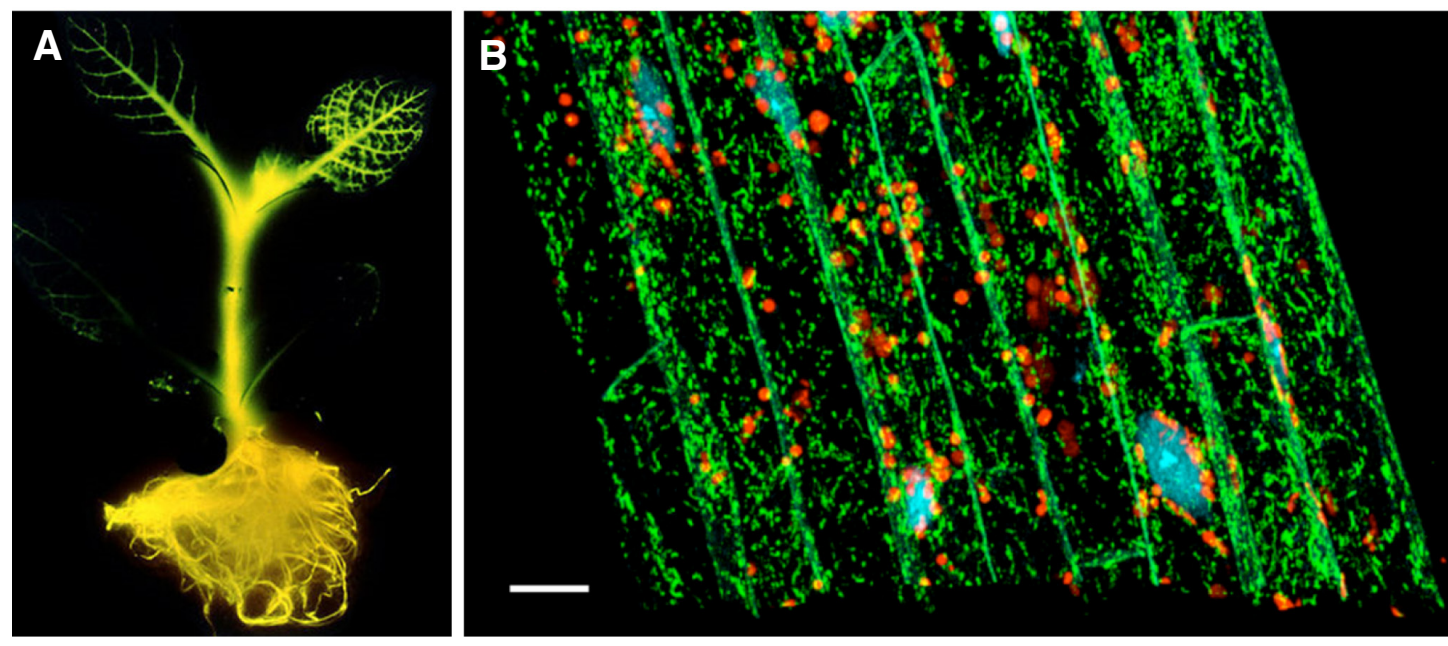

Fig. 1. Transgenic reporter plants. (A) Autoradiograph of the first transgenic plant to express a light-emitting reporter: a tobacco plant expressing the firefly luciferase gene (image from Ow et al., 1986). (B) Confocal laser scanning micrograph of a root of the Arabidopsis reporter line Kaleidocell limage from Kato et al., 2008) in which cell walls are marked with GFP, mitochondria with YFP, plastids with RFP, and nuclei with CFP. Scale bar: $10 \mu \mathrm{m}$. Note that the GFP and YFP signals were collected in the same channel and hence not isolated.

subsequently found that correct expression of GFP is confounded in Arabidopsis by aberrant mRNA processing in which a cryptic intron is excised from the transcript resulting in a non-fluorescent protein (Haseloff and Amos 1995). Once the sequences involved in splice-site recognition of this intron were mutated, full GFP function was restored (Haseloff et al., 1997).

\section{Re-engineering fluorescent proteins}

In parallel with the developments in adapting GFP for use in plantae, the protein was also the subject of intense research to increase its utility. Wild type GFP has excitation maxima at both 396 and $475 \mathrm{~nm}$ (Chalfie et al., 1994; Table 1), preventing its use as a resonance energy transfer acceptor. Replacing the serine at position 65 with a threonine produced an FP with a single excitation peak at $489 \mathrm{~nm}$ with an amplitude six times that of wild type and a slight shift of the emission maximum to $511 \mathrm{~nm}$ (Heim et al., 1995). Adoption of this re-engineered GFP was aided by the fact that the widely-used fluorescent dye fluorescein isothiocyanate (FITC) has excitation and emission spectral maxima at 495 and $519 \mathrm{~nm}$ respectively, making the S65T GFP variant compatible with existing hardware filter sets. Favoured codon optimisation of the S65T sequence produced a modified GFP that fluoresced 100-fold brighter than wild type (Chiu et al., 1996). Researchers at Clontech Laboratories Inc. engineered "enhanced" GFP (EGFP), incorporating several mutations (including S65T) to produce a variant with improved fluorescence intensity. This variant also included 190 silent base mutations to allow more efficient EGFP mRNA translation in mammalian and plant cells and hence higher expression (Yang et al., 1996).

\section{Not just green - creating a fluorescence palette}

In addition to the optimisation of GFP, much of the effort in modifying wild type GFP was directed to the production of FPs that emit at different wavelengths (colours). Multiple emission colours allow simultaneous isolation of individual target genes, the creation of donor/acceptor pairs for fluorescence resonance energy transfer (FRET) and multicolour labelling of organelles. Variants of GFP have been produced that fluoresce orange, yellow and cyan (though note that these colour designations do not often follow the recognised spectral wavelength ranges and are commonly used to distinguish groupings of FPs). With a single published exception (Mishin et al., 2008), the emission maxima of GFP variants have been limited to wavelengths up to $529 \mathrm{~nm}$, leading researchers to hunt for GFP homologues in other organisms for suitable candidates with fluorescence emission towards the red end of the spectrum, with most success coming from proteins from corals of the genus Discosoma (Bevis and Glick 2002; Shaner et al., 2004). The photoconvertible FP Kaede was isolated from another coral, Trachyphyllia geoffroyi (Ando et al., 2002). The utility of FPs emitting at different wavelengths is illustrated by the Arabidopsis "Kaleidocell" line (Kato et al., 2008) in which nuclei, plastids, mitochondria, and plasma membranes are tagged with cyan, red, yellow and green fluorescent proteins, respectively (Fig. 1B). The most useful examples of FPs in each colour range are summarised in Table 1.

\section{Applications of fluorescent proteins in plant biology}

Following the optimisation of FPs for use in Arabidopsis, further challenges had to be overcome before FPs could be widely used in plants. Chlorophyll, lignified secondary cell walls and vacuolar contents all display autofluorescence overlapping with the emission wavelength of GFP which thus has to be taken into account when planning and performing experiments (Gunning and Schwarz, 1999; Berg, 2004; Berg and Beachy, 2008). GFP is a relatively small protein $(27 \mathrm{kDa})$ and can passively diffuse through plasmodesmata (Grebenok et al., 1997, Itaya et al., 2000; Crawford and Zambryski, 2001). Unwanted diffusion (when promoter fusions are used) can be avoided by using repeats, such as three GFPs fused together (3xGFP) or by adding specific subcellular localisation signals as HDEL/KDEL endoplasmic reticulum targeting sequences, nuclear localisation signals (NLS), or others (Gomord et al., 1997; Grebenok et al., 1997; Haseloff et al., 1997; Chytilova et al., 1999). The combination of 3xGFP with an NLS not only increases fluorescence but by concentrating it to the nuclei also facilitates imaging of targets with low expression levels. Cellular retention of 3xGFP can also be exploited to study cell to cell transport of transcription factors (Nakajima et al., 2001).

The use of FP markers in modern plant molecular biology has increased dramatically over the last two decades. With a large selection of FPs and the availability of sophisticated image acquisition hardware and analysis software, not only co-localisation 
analyses but also quantitative measurements and determination of polar distribution of FPs are achievable. Numerous FP fusions localizing to specific organelles have been produced (Nelson et al., 2007; Geldner et al., 2009; Kato et al., 2008: see Fig. 1B) and the generation of new fusions is simple using freely-available vectors (Karimi et al., 2007; De Rybel et al., 2011; Zhou et al., 2011). Once transgenic plant lines expressing one or more FPs have been generated, protein dynamics at the subcellular level (from individual protein to organelle) can be investigated in vivo. Using FP fusions, it is possible to visualise the expression pattern and the subcellular localisation of one or more proteins and to compare changes in expression or localization in mutants or samples under different experimental conditions (abiotic stresses, hormone treatments, etc.). Such studies allow detailed examination of protein dynamics, function or interaction in regulatory and developmental processes. In plant developmental research, 3D timelapse imaging with carefully chosen marker proteins allows the monitoring of developmental processes or cell division patterns in vivo without disruption to the process under study.

Individual cell types can be labelled by using enhancer- or gene trap lines such as the GAL4-UAS system originally developed in Drosophila and subsequently optimised for use in plants (Haseloff, 1999). These lines contain an enhancer trap module consisting of a minimal promoter driving the yeast transcription factor GAL4 with a coding sequence optimized for plants and an endoplasmic reticulum (ER) localised GFP reporter (mGFP5-ER) controlled by the GAL4 response upstream activating sequence (UAS). Upon insertion of the construct in close proximity to a tissue specific enhancer element, GAL4 will be expressed which then activates mGFP5-ER expression (Haseloff, 1999). These lines allow live imaging in genetic and developmental studies and can also be used for tissue specific expression or targeted misexpression of a particular gene (reviewed in Acosta-Garcia et al., 2004). Enhancer- or gene trap lines have also been used for tissue specific transcriptomic and proteomic studies and hormone quantification (reviewed in Moreno-Risueno et al., 2010; Pu and Brady, 2010) using fluorescence activated cell sorting (FACS; Haseloff, 1999; Birnbaum et al., 2003; Petersson et al., 2009). This can lead to the identification of tissue specific regulatory sequences (Tsugeki and Fedoroff, 1999). GAL4-UAS enhancer trap transactivation based insertion collections have been generated for Arabidopsis and are freely available from donor laboratories and stock centres.

\section{Imaging protein dynamics}

Protein dynamics can be visualised in detail in vivo by using FPs and the techniques of photobleaching, photoactivation and photoconversion/photoswitching (see review in Sparkes, 2010). In photobleaching experiments, the protein structure of the FP is irreversibly changed by illumination from a high intensity light source (usually a laser). This structural change halts fluorescence (Swift and Trinkle-Mulcahy, 2004). Once targeted FPs have been bleached, fluorescent recovery over time (FRAP) can be monitored. This return of fluorescence is due to the movement of unbleached proteins to the affected area or to the synthesis of de novo FPs. To distinguish between those two possibilities, treatment with the protein-synthesis inhibitor cycloheximide can be used to limit recovery only to movement of unbleached proteins. FRAP experiments are often paired with FLIP (fluorescence loss in photobleaching) assays which, instead of measuring the recovery in fluorescence, monitor a decrease in fluorescence in a region adjacent to the bleached area. As an alternative to selective photobleaching, protein mobility can also be assessed by monitoring selective activation of fluorescence in proteins tagged with photoactivatable GFP (PAGFP; Lippincott-Schwartz and Patterson, 2009). Upon irradiation with ultraviolet light, the fluorescence of PAGFP dramatically increases. The use of photobleaching and photoactivation techniques not only allows the dynamics of individual proteins to be studied, it also permits the study of physical membrane properties if integral membrane proteins are tagged (Ward and Brandizzi, 2004; Held et al., 2008). Photoconvertible or photoswitchable fluorophores exhibit a shift in emission wavelength upon excitation, allowing monitoring of both the unconverted and converted pool of proteins in the same sample (Lippincott-Schwartz and Patterson, 2009). For example, fluorescence of the photoconvertible protein Kaede (isolated from the coral Trachyphyllia geoffroyl) changes irreversibly from green to red upon activation with ultraviolet light (Brown et al., 2010, Table 1).

\section{Protein-protein interactions}

A wide range of techniques are available to study protein-protein interactions in plants. However, many operate only in vitro such as yeast two-hybrid screening or co-immunoprecipitation and therefore may not reflect the situation in planta. In contrast, FP based methods can be performed in vivo and also take protein localisation of putative binding partners into account.

TABLE 1

\section{FLUORESCENT PROTEINS}

\begin{tabular}{|c|c|c|c|c|c|}
\hline Fluorescence & Protein & Origin & Excitation $\mathrm{nm}$ & Emission nm & Reference \\
\hline Far-red & mPlum & Discosoma sp. & 590 & 649 & Wang et al., 2004 \\
\hline Red & $\begin{array}{l}\text { mCherry } \\
\text { DsRed }\end{array}$ & $\begin{array}{l}\text { Discosoma sp. } \\
\text { Discosoma sp. }\end{array}$ & $\begin{array}{l}587 \\
556\end{array}$ & $\begin{array}{l}610 \\
586\end{array}$ & $\begin{array}{l}\text { Shaner et al., } 2004 \\
\text { Matz et al., } 1999\end{array}$ \\
\hline Orange & mOrange & Discosoma sp. & 548 & 562 & Shaner et al., 2004 \\
\hline Yellow & $\begin{array}{l}\text { EYFP } \\
\text { VENUS } \\
\text { YPet }\end{array}$ & $\begin{array}{l}\text { Aequorea victoria } \\
\text { Aequorea victoria } \\
\text { Aequorea victoria }\end{array}$ & $\begin{array}{l}514 \\
515 \\
517\end{array}$ & $\begin{array}{l}527 \\
528 \\
530\end{array}$ & $\begin{array}{l}\text { Tsien } 1998 \\
\text { Nagai et al., } 2002 \\
\text { Nguyen \& Daugherty } 2005\end{array}$ \\
\hline Green & $\begin{array}{l}\text { GFP } \\
\text { EGFP } \\
\text { EmGFP }\end{array}$ & $\begin{array}{l}\text { Aequorea victoria } \\
\text { Aequorea victoria } \\
\text { Aequorea victoria }\end{array}$ & $\begin{array}{c}396,475 \\
488 \\
487\end{array}$ & $\begin{array}{l}507 \\
507 \\
509\end{array}$ & $\begin{array}{l}\text { Chalfie et al., } 1994 \\
\text { Yang et al., } 1996 \\
\text { Tsien } 1998\end{array}$ \\
\hline Cyan & $\begin{array}{l}\text { mCFP } \\
\text { Cerulean } \\
\text { CyPet }\end{array}$ & $\begin{array}{l}\text { Aequorea victoria } \\
\text { Aequorea victoria } \\
\text { Aequorea victoria }\end{array}$ & $\begin{array}{l}433 \\
433 \\
435\end{array}$ & $\begin{array}{l}475 \\
475 \\
477\end{array}$ & $\begin{array}{l}\text { Zacharias et al., } 2002 \\
\text { Rizzo et al., } 2004 \\
\text { Nguyen \& Daugherty } 2005\end{array}$ \\
\hline Green/red & Kaede & Trachyphyllia geoffroyi & $\begin{array}{l}508 \\
572\end{array}$ & $\begin{array}{l}518 \\
582\end{array}$ & $\begin{array}{l}\text { Ando et al., } 2002 \\
\text { on UV excitation }\end{array}$ \\
\hline
\end{tabular}

Commonly-used FPs (adapted from Shaner et al., 2005 and Ckurshumova et al., 2011). 
Förster or fluorescence resonance energy transfer (FRET) measures the energy transfer between a donor and an acceptor fluorophore. A prerequisite for FRET is that the donor's emission spectrum overlaps with the excitation spectrum of the acceptor. Potential fluorophore pairs are GFP with monomeric red fluorescent protein (RFP), and cyan fluorescent protein (CFP) with yellow fluorescent protein (YFP). These are each fused to one of the putative interacting proteins. If these proteins are in very close proximity $(1-10 \mathrm{~nm})$, energy is non-radiatively transferred from the donor to the acceptor fluorophore leading to fluorescence quenching in the donor and increase in the acceptor (Wallrabe and Periasamy, 2005). Over the last decade, FRET has been successfully combined with fluorescence lifetime imaging (FLIM) in plantae (Wallrabe and Periasamy, 2005; Swift andTinkle-Mulcahy, 2004; Held et al., 2008). FLIM is based on each fluorophore having an unique lifetime, defined as the average time the molecule remains in an excited state before returning to the ground state (Chen et al., 2003). This lifetime is not affected by the concentration of the fluorophore or excitation intensity (Wallrabe and Periasamy, 2005), but can be influenced by changes in $\mathrm{pH}$, temperature, calcium ion concentration and FRET occurrence (Chen et al., 2003). Importantly, FRET-FLIM can produce additional spatial and temporal information for protein interactions that might not be obtained with other techniques (Osterrieder et al., 2009).

Alternatively, split protein systems or bimolecular fluorescence (BiFC) can be used for quantitative and qualitative studies of protein-protein Interactions in vivo. Most existing FPs have been used to create split reporters and have been used to investigate the dynamics of many protein-protein interactions (reviewed in Muller and Johnsson, 2008). Upon protein interaction, the two FP fragments come into close proximity and the FP is reconstituted. The resulting fluorescent signal can then be analysed by confocal laser scanning microscopy. Because of the large range of available fluorophores it is also possible to image multiprotein complex interactions in the same cell (Weinthal and Tzfira, 2009). However, when designing experiments and analysing their results one needs to be aware that the binding of the reassembled GFP domains is irreversible and therefore the temporal dynamics of the investigated proteinprotein interactions cannot be monitored. However this can also be an advantage when weak interactions are monitored. (Magliery et al., 2005; Nyfeler et al., 2005). Unlike FP-based approaches, split-luciferase reporters are reversible (Porter et al., 2008) and have been successfully adapted to establish membrane protein topology (Zamyatnin et al., 2006).

\section{Visualising fluorescent proteins in plants}

If driven by a strong promoter, GFP fluorescence in transgenic plants can be visualised with the naked eye. This is especially simple if using a variant with the wild type excitation peak at 395 $\mathrm{nm}$ as illumination with UV light results in emission that does not require filtering to exclude the exciting light as it is invisible to the human eye. If using one of the engineered variants with a single excitation peak, suitable filters must be used to mask the excitation wavelengths from the detection/viewing system. Benchtop and hand-held fluorometers have been developed to quantify fluorescence and whole plant fluorescence can even be monitored remotely using stand-off laser-induced spectrometry (see review in Millwood et al., 2008). The most widely-used instruments for visualising FPs in plantae however are microscopes, ranging from simple epifluorescence devices to highly complex laser scanning confocal instruments.

\section{Advances in fluorescent microscopy}

The recent advances in methods based on FP markers have only been made possible by parallel improvements in fluorescent microscopy techniques and image acquisition and analysis software. Researchers now have a choice between a wide range of imageacquisition techniques at different resolutions and throughput, based on their experimental requirements. In this section we will give a brief description of the principles of operation and the advantages and disadvantages of various microscope technologies.

Widefield fluorescence microscopy is the cheapest and simplest fluorescence imaging system available. It generates images by collecting photons from multiple focal planes. As a result, images are often of lower quality compared to the techniques discussed below. Pictures are blurry, as out of focal plane photons are collected as well, leading to lower image contrast and resolution (Swedlow and Platani, 2002).

Confocal laser scanning microscopy (one photon) is based on beam-scanning microscopy in which a single photon provides energy to linearly excite a fluorophore. Regions of the sample above and below the focal plane are also exposed to the excitation illumination, resulting in excitation of fluorescence outside of the focal plane. To overcome the problem of a blurry, unsharp image, a pinhole rejects out of focus fluorescence. Increasing pinhole size to compensate for low excitation and emission results in lower Z-axis resolution. To obtain 3D pictures, the specimen can be imaged in many different layers of the Z-axis (Z-stack), but as a consequence a longer time is required for image acquisition which can result in photobleaching and photodamage of the subject (Pawley, 1995; Periasamy etal., 1999; Rubart, 2004). Spinning disc confocal microscopy overcomes some of the limitations of confocal microscopy by scanning the entire image simultaneously and collecting fluorescence through numerous pinholes. This allows faster image acquisition, and a reduction of photobleaching of up to 15-fold (Ichiara et al., 1996; Wang et al., 2005)

In two-photon and multiphoton microscopy, two or more long wavelength photons are absorbed around the focal point, leading to non-linear excitation of the fluorophore. In contrast to single photon confocal laser scanning microscopy, excitation of fluorescence is restricted to the focal plane and consequently a pinhole is not required. The limited excitation reduces photobleaching and photodamage to the imaged cells. These features make multiphoton microscopy the technique of choice for experiments where repetitive or prolonged laser exposure are required, such as time lapse and live imaging. Another advantage of multiphoton microscopy is the ability of longer wavelength photons to penetrate deeper into the tissue, beneficial when working with thicker samples (Denk et al., 1990; Potter et al., 1996; Centoze and White, 1998; Periasamy et al., 1999; Rubart, 2004).

Another novel microscopy technique that reduces sample bleaching is light-sheet microscopy (also known as selective-plane illumination microscopy or SPIM). A rotating sample is illuminated with a thin light sheet. The resulting fluorescence is collected with an objective positioned perpendicularly to the sheet. This arrangement exposes only the object plane being imaged to the excitation light. Therefore the light-dose is lower than in conventional 
microscopes (as only the plane being imaged is illuminated) and as a result specimens suffer far less photodamage, allowing longterm high-resolution imaging of intact plants. The use of the light sheet also detects fluorescence over the entire field of view and therefore makes $x-y$ scanning unnecessary, resulting in a faster image acquisition time (Maizel et al., 2011; Sena et al., 2011).

The development of these highly sophisticated fluorescence microscopes reflects the demand from the scientific community for more complex and detailed imaging. Together with improved fluorescent tags, scientists now have a complete set of tools to study rapid (in the range of seconds/minutes) and dynamic developmental process. Recently, a new fluorescent sensor that quantifies bioactive auxin in plant tissues in vivo and over time to a degree not hitherto attained has been developed (Vernoux et al., 2011; Brunoud et al., 2012). The numerous benefits of this new tool for plant scientists raise the fascinating question of whether a similar approach can be applied to develop sensors for other hormones.

\section{Fluorescent biosensors for plant hormones}

In order to quantify the dynamic distribution of plant hormones, transgenic plants have been engineered to express FPs in the presence or absence of a specific signal (Jach, 2006). These reporters usually rely on endogenous or, in cases such as auxin and the DR5 sequence where hormone-specific regulatory motifs are known, synthetic promoters (Ulmasov et al., 1997). These promoters drive the expression of an FP, which can have any particular properties of interest (see sections above). As FPs can be followed over time using confocal or fluorescent microscopes and because such reporter lines can easily be crossed into mutant backgrounds of interest, they have allowed the study of detailed dynamic changes in hormone signalling at the cellular level. It is important to note that it is neither the hormone itself nor the input to the signalling pathway which is measured in such systems, but the overall output of the signalling cascade and this can have considerable disadvantages (for a review of these concepts, see Okumoto et al., 2012 and Wells et al., 2013). The transcription, translation and maturation of the FP will have a profound effect on reporter expression as these processes may vary between tissues or environmental conditions. Secondly, if downstream FPs are expressed in cells that are responding to a specific signal, it would be naïve to expect that these are not affected to some degree by additional, non-specific signals. These effects may differ in particular genetic backgrounds due to ecotype specific properties, a common problem in Arabidopsis (Fu et al., 2009), and are very hard to control. Finally, and probably of greatest importance, is the time required to express a fully mature FP from mRNA, which under standard plant growth conditions takes about 2 hours at $23^{\circ} \mathrm{C}$ for the fast maturing FP VENUS (Brunoud et al., 2012; Nagai et al., 2002; Table 1).

This is even more relevant when considering dynamic developmental processes in plants, such as root gravitropism (Swarup et al., 2013). Plant roots usually grow following the gravity vector, regulated by the redistribution of the plant hormone auxin from the root tip into the elongation zone (Swarup et al., 2005). In the "normal" situation, where roots grow following the gravity vector, fluxes of auxin are equal around the root tip. This can be visualised using the synthetic auxin reporter DR5 driving the expression of GFP (Wolverton et al., 2011). If this flux changes, for example following a $90^{\circ}$ gravity stimulus, auxin accumulates on the lower part of the root and is depleted in the upper part (Rashotte et al., 2001). This redistribution leads to a tropic response whereby roots re-orientate their growth towards gravity (Thimann, 1935). This is a highly dynamic process: a root starts to respond within 10 minutes after a gravistimulus and grows straight again in a matter of hours (Wolverton et al., 2011). Because of the time delay to produce a mature fluorescent GFP, a DR5::GFP reporter only starts to show a differential distribution when the gravitropic response is well established. To overcome this, Wolverton and colleagues used a rotating platform to maintain roots at a constant angle to the gravity vector and imaged fluorescence at set time points (Wolverton et al., 2011). However, such an experimental set up is only applicable for the study of root gravitropism, which, irrespective of the quality of the data reported, limits its utility. In order to reveal these dynamic processes it is the design of the reporter itself that has to be optimised (Wells et al., 2013).

Recently, Vernoux and colleagues (Vernoux et al., 2011; Brunoud et al., 2012) engineered a new fluorescent auxin sensor that responds within minutes of exogenous auxin application. This new sensor works in a completely different way from the reporters described so far as fluorescence is not induced by the target signal but degraded in its presence. This exploits the fact that genomic auxin responses rely mainly on the degradation of repressor proteins called IAAs (Chapman and Estelle, 2009). IAA proteins have been shown to interact via their domain II (DII or degron) in an auxin-dependent manner with a sub-class of F-BOX Ubiquitin E3 ligase, of which there are 6 members in Arabidopsis: AFBs 1-5 and TIR1 (Tan et al., 2007). When the interaction is strong (i.e. abundant bioactive auxin), the half-lives of IAA proteins are dramatically reduced, varying from 11 minutes (for IAA1 and 17) to up to 80 minutes (for IAA28) (Dreher et al., 2006). Therefore, auxin response correlates with the turnover of IAA proteins: If IAA levels are high, auxin responses are low and vice versa (Tiwari et al., 2001). Unfortunately, because the maturation time of common FPs is longer than the half-life of IAA proteins it has not been possible to observe IAA-FP fusion proteins on a fluorescent or confocal microscope. However, using VENUS (see Table 1) and the DII domain of the most stable yet auxin sensitive IAA protein (IAA28), Vernoux and colleagues were finally able to "see" a native IAA-FP fusion protein in vivo for the first time (Vernoux et al., 2011; Brunoud et al., 2012). Importantly, the DII-VENUS reporter does not measure the output of the auxin response pathway (as do reporters based on DR5) but is directly related to the input to the pathway, i.e. the bioactive signal itself. Fig. 2 shows the distribution of the DII-VENUS input reporter and a DR5::3xVENUS output reporter in Arabidopsis root tips (Fig. 2A, left and right panels respectively).

\section{DII-VENUS: a "model" biosensor?}

The initial characterisation showed that the DII-VENUS reporter is an ideal auxin sensor (Band et al., 2012, Brunoud et al., 2012, Vernoux et al., 2011). Firstly, it is broadly expressed, at least in root tissues, via the constitutive cauliflower mosaic virus (CaMV) $35 S$ promoter, with fluorescence localised to the nucleus due to an NLS (Fig. 2A left panel). Critically, DII-VENUS is degraded in a dose dependent manner when treated with exogenous auxin (Fig. 2B upper panel) and this is furthermore specific to bioactive auxins, since inactive variants do not have any effect. It also requires active receptors (TIR1 and AFB1-3) and a wild type DII, 
as mutations in key amino acids known to stabilise IAA proteins stabilise the sensor as well. The main advantage of this reporter is its speed of response. A decrease in DII-VENUS fluorescence can be detected within minutes of exogenous auxin production (Fig. 2B upper panel); in contrast a DR5-based reporter takes over $2 \mathrm{~h}$ for an increase in fluorescence to be detected (Fig. 2B lower panel). Using DII-VENUS, the dynamic redistribution of auxin during root gravitropism can thus be visualised even before the root starts to re-orientate its growth towards the gravity vector (Brunould et al., 2012; Band et al., 2012).

As with every new approach there are drawbacks that must be taken into account when designing experiments. It has been shown that DII-VENUS interacts with auxin receptors in plantae (Brunoud et al., 2012). Because the transgene is highly overexpressed by the 35 S promoter, it is possible that it occupies all the receptors available in the nucleus. However, it has been shown that overexpressing the DII-VENUS sensor does not affect gravitropism itself, as transgenic plants behave identically to their wild type counterparts, suggesting this not to be a problem (Brunoud etal., 2012). Furthermore, although CaMV $35 S$ is a strong promoter, it is not ubiquitously expressed, especially in the embryo (Odell et al., 1985), and very often leads to silencing of the transgene after several generations (Daxinger et al., 2008). These problems may be circumvented by employing a different promoter less prone to silencing. For example, the RPS5A
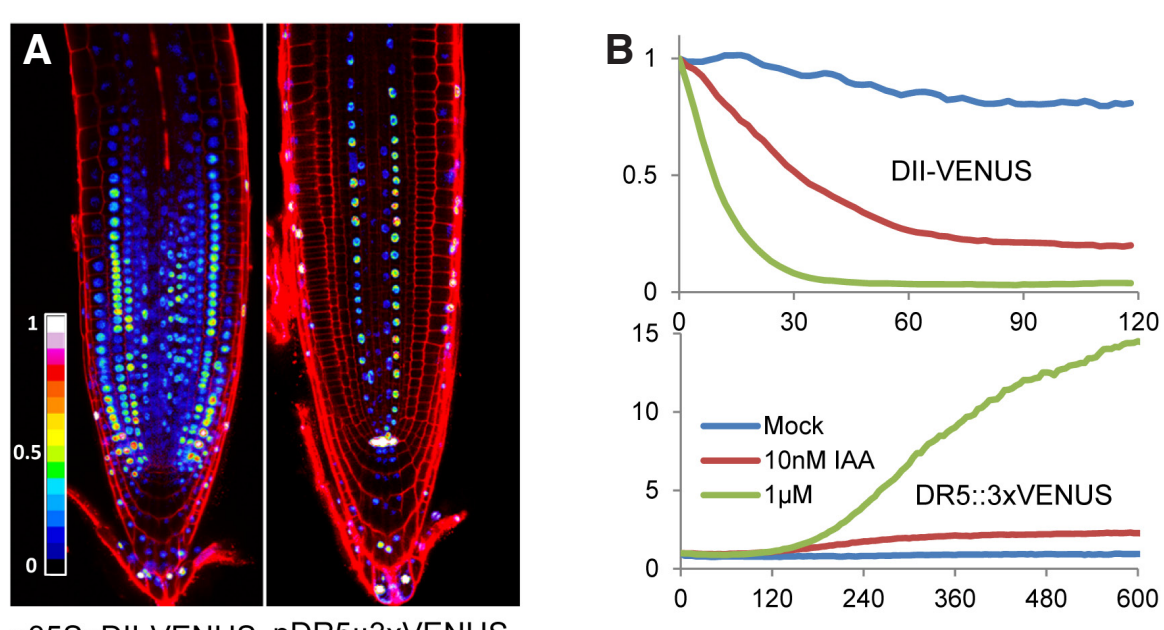

p35S::DII-VENUS pDR5::3xVENUS

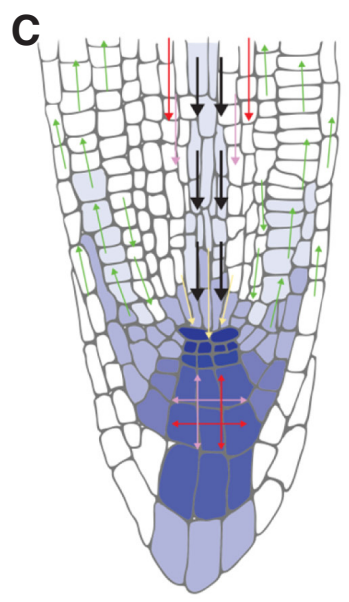

Auxin concentration gradient
D

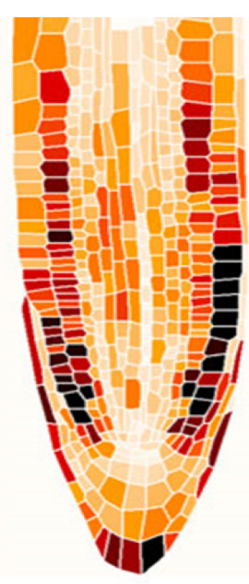

Relative auxin

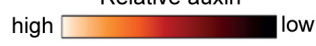

E

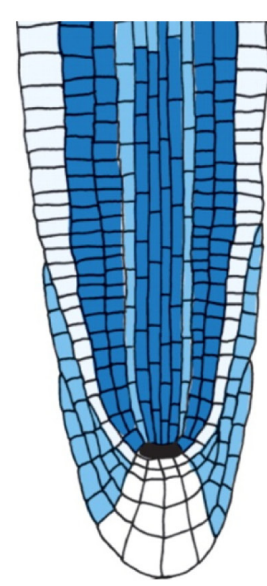

0 0 promoter is strongly expressed in the embryo but then reduces in more mature tissues after germination (Weijers et al., 2001). Unfortunately, there are probably no ideal promoters, a limitation shared by both input and output reporter systems.

The degradation of DII-VENUS requires an active receptor which in the case of auxin involves not only the receptor itself but the whole SCF (Skp1, Cullin and F-BOX) complex (Chapman and Estelle, 2009). In the root, it has been shown that the lateral root cap has a lower sensitivity to auxin and that this is most likely due to reduced expression of receptor complexes in this tissue (Brunoud et al., 2012). Therefore, the sensor does not directly reflect the endogenous auxin but also reflects the sensitivity of cells to auxin. To measure actual hormone abundance, one can employ techniques such as gas chromatography followed by mass spectrometry (GC/MS) (Edlund et al., 1995). However, because large amounts of tissues are required, whole plants are often used or, in best cases, specific organs. Consequently, the spatial distribution of the signal being measured cannot be determined. To improve spatial resolution, Petersson and colleagues (Petersson et al., 2009) have successfully combined GC/MS with protoplasting and fluorescent activated cell sorting (FACS) approaches to quantify auxin and its metabolites in specific tissues (Fig. 2E). Even though the quality of the data produced was very high, there are several issues associated with this approach. Firstly, because it relies on the enrichment of individual cell types, the technique does not reveal the tissue specific auxin gradients at the root apical meristem which are key in regulating the transition between the different regions of the root tip. Secondly, the length ( 2 hours) and harshness of the protoplasting treatment prevents the monitoring of dynamic changes in auxin abundance. Finally, it is a destructive approach, preventing the monitoring of a particular tissue over time. Fig. 2 C-E shows maps of auxin distribution in the root tip produced using the DR5 output reporter (Fig. 2C), DII-VENUS (Fig. 2D) and FACS (Fig. 2E). Note the complementarity between the input and output reporters and the high spatial resolution of the map generated using DII-VENUS.

As DII-VENUS fluorescence reduces with the abundance of its target, it may be difficult to follow the signal over time unless a background nuclear marker, such as histone $2 \mathrm{~B}$ fused to RFP, is pres-

Fig. 2. DII-VENUS responds rapidly to auxin and reveals auxin distribution at high spatial resolution. (A) Confocal laser scanning micrograph of Arabidopsis roots expressing the DII-VENUS (left) and the DR5::3xVENUS reporter (right) (unpublished data). (B) Changes in VENUS fluorescence in DII-VENUS (top) and DR5::3xVENUS (bottom) in response to various auxin concentrations (unpublished data). X-axis: time (in minutes, note the scale is different between charts); y-axis: normalised relative fluorescence. (C-E) Maps of auxin distribution obtained using (C) the DR5 reporter (image from Krecek et al., 2009), (D) the DII-VENUS biosensor (Brunoud et al., 2012), or (E) by direct quantification of IAA (indole-3-acetic acid) using GC/ MS on sorted protoplasts (Petersson et al., 2009). bg, background level. 
ent (Federici et al., 2012). This is not an ideal control, however, since even when using the same promoter for both reporters, there is no guarantee that their expression will be identical and linear. Despite these limitations this new generation of fluorescent biosensors have provided the opportunity to image the dynamics of hormone signalling in vivo at a resolution that has not been achieved before. To relate imaged DII-VENUS fluorescence to auxin abundance required the development of parameterised mathematical models as the relationship is non-linear (Band et al., 2012). In order to monitor plant roots responding to a gravistimulus in a realistic environment, the authors adapted an inverted confocal microscope to image roots arranged vertically on growth plates. Using experimental time course data together with the parameterised model, they showed that auxin distribution changes rapidly and only transiently between the upper and lower sides of the root and that the system returns to steady state at a set angle from the gravity vector. Such detailed observations have previously not been possible and are the result of combining state of the art confocal microscopy techniques, novel engineered fast-maturing and bright FPs, and mathematical models to simulate complex signalling pathways.

\section{Conclusions and Perspectives}

The availability of a variety of multi-coloured FPs has revolutionised many aspects of plant research over the last two decades. The development of both the reporters themselves and the systems used to image and quantify them has progressed at a great pace, and almost certainly will continue to do so.

The data derived from DII-VENUS fluorescence is an excellent demonstration of how FP technology has improved our understanding of fundamental biological processes. Interestingly, the main feature of auxin signalling - the regulated turnover of repressor proteins via an F-BOX E3 ubiquitin ligase complex - is found in the response pathways for other hormones such as jasmonates (JAZ repressors, COI1 F-BOX ligase), and gibberellins (DELLA repressors, SLY F-BOX ligase). The approach used to develop DII-VENUS can potentially be employed to study other hormone responses, offering researchers the prospect of new fluorescent biosensors for the study of plant developmental processes.

New techniques and insights are being brought to bear on both the design of biosensors based on FPs and the techniques used to interpret fluorescence data and it is certain that they will remain an essential part of the plant researcher's toolkit for many years to come.

\section{Acknowledgements \\ We apologise to colleagues whose work could not be cited due to space limitations. The authors acknowledge the support of the Biotechnology and Biological Sciences Research Council (BBSRC) and Engineering and Physical Sciences Research Council (EPSRC) funding to the Centre for Plant Integrative Biology (CPIB), BBSRC responsive mode grant support to UV and AL, and Belgian Scientific Policy (Belgian Arabidopsis Root Network) grant to $A L$.}

\section{References}

ACOSTA-GARCIA G, AUTRAN D and VIELLE-CALZADA J P. (2004). Enhancer detection and gene trapping as tools for functional genomics in plants. Methods Mol Biol 267: 397-414.

ANDO R, HAMAH, YAMAMOTO-HINO M, MIZUNOH, MIYAWAKIA(2002). An optical marker based on the UV-induced green-to-red photoconversion of a fluorescent protein. Proc Natl Acad Sci USA 99: 12651-12656.

BAND LR, WELLS DM, LARRIEU A, SUN J, MIDDLETON AM, FRENCH AP, BRUNOUD G, SATO EM, WILSON MH, PERET B et al., (2012). Root gravitropism is regulated by a transient lateral auxin gradient controlled by a tipping-point mechanism. Proc Natl Acad Sci USA 109: 4668-4673.

BAZELL R, PALMER J (1986). Tobacco plant lights up after scientists insert firefly gene. [Television series episode]. NBC Today Show. Retrieved from: https:// archives.nbclearn.com/portal/site/k-12/browse/?cuecard $=41482$

BERG R H. (2004). Evaluation of spectral imaging for plant cell analysis. J Microsc 214: 174-181.

BERG R H and BEACHY R N. (2008). Fluorescent protein applications in plants. Methods Cell Biol 85: 153-177.

BEVIS BJ and GLICK BS (2002). Rapidly maturing variants of the Discosoma red fluorescent protein (DsRed). Nat Biotechnol, 20: 83-87.

BIRNBAUM K, SHASHA D E, WANG J Y, JUNG J W, LAMBERT G M, GALBRAITH D W and BENFEY P N. (2003). A gene expression map of the Arabidopsis root. Science 302: 1956-1960.

BROWN S C, BOLTE S, GAUDIN M, PEREIRA C, MARION J, SOLER M N and SATIAT-JEUNEMAITRE B. (2010). Exploring plant endomembrane dynamics using the photoconvertible protein Kaede. Plant J 63: 696-711.

BRUNOUD G, WELLS DM, OLIVA M, LARRIEU A, MIRABET V, BURROW AH, BEECKMAN T, KEPINSKI S, TRAAS J, BENNETT MJ et al., (2012). A novel sensor to map auxin response and distribution at high spatio-temporal resolution. Nature 482: 103-106.

CENTOZE VE, WHITE JG (1998). Mulltiphoton excitation provides optical sections from deeper within scattering specimens than confocal imaging Biophys. J. 75: 2015-2024.

CHALFIE M, TU Y, EUSKIRCHEN G, WARD WW, PRASHER DC (1994). Green fluorescent protein as a marker for gene expression. Science 263: 802-805.

CHAPMAN EJ and ESTELLE M. (2009). Mechanism of auxin-regulated gene expression in plants. Ann. Rev. Genet. 43: 265-285.

CHEN Y, MILLS J D and PERIASAMY A. (2003). Protein localization in living cells and tissues using FRET and FLIM. Differentiation 71: 528-541.

CHIUWL, NIWAY, ZENG W, HIRANO T, KOBAYASHIH, SHEEN J (1996). Engineered GFP as a vital reporter in plants. Curr Biol 6: 325-330.

CHYTILOVA E, MACAS J, GALBRAITH DW (1999). Green fluorescent protein targeted to the nucleus, a transgenic phenotype useful for studies in plant biology. Ann. Bot. 83:645-654.

CKURSHUMOVA W, CARAGEA AE, GOLDSTEIN RS, BERLETH T (2011). Glow in the dark: fluorescent proteins as cell and tissue-specific markers in plants. Mol. Plant 4: 794-804.

CRAWFORD K M and ZAMBRYSKI P C. (2000). Subcellular localization determines the availability of non-targeted proteins to plasmodesmatal transport. Curr Biol 10: 1032-1040.

CRAWFORD K M and ZAMBRYSKI P C. (2001). Non-targeted and targeted protein movement through plasmodesmata in leaves in different developmental and physiological states. Plant Physiol 125: 1802-1812.

DAXINGER L, HUNTER B, SHEIKH M, JAUVION V, GASCIOLLI V, VAUCHERET H, MATZKE M and FURNER I. (2008). Unexpected silencing effects from T-DNA tags in Arabidopsis. Trends Plant Sci 13: 4-6.

DE RYBEL B, VAN DEN BERG W, LOKERSEA, LIAO C Y, VAN MOURIKH, MOLLER $B$, PERIS $C L$ and WEIJERS D. (2011). A versatile set of ligation-independent cloning vectors for functional studies in plants. Plant Physiol 156: 1292-1299.

DENK W, STRICKLER J H and WEBB W W. (1990). Two-photon laser scanning fluorescence microscopy. Science 248: 73-76.

DREHER KA, BROWN J, SAW RE and CALLIS J. (2006). The Arabidopsis Aux/IAA protein family has diversified in degradation and auxin responsiveness. Plant Cell 18: 699-714.

EDLUND A, EKLOF S, SUNDBERG B, MORITZ T and SANDBERG G. (1995). A Microscale Technique for Gas Chromatography-Mass Spectrometry Measurements of Picogram Amounts of Indole-3-Acetic Acid in Plant Tissues. Plant Physiol 108: 1043-1047.

FEDERICIF, DUPUY L, LAPLAZE L, HEISLER HAND HASELOFFJ (2012). Integrated genetic and computation methods for in planta cytometry. Nat Meth 9: 483-485. 
FU J, KEURENTJES JJ, BOUWMEESTER H, AMERICA T, VERSTAPPEN FW, WARD JL, BEALE MH, DE VOS RC, DIJKSTRA M, SCHELTEMA RA et al., (2009). System-wide molecular evidence for phenotypic buffering in Arabidopsis. Nat Genet 41: 166-167.

GELDNER N, DENERVAUD-TENDON V, HYMAN D L, MAYER U, STIERHOF Y D and CHORY J. (2009). Rapid, combinatorial analysis of membrane compartments in intact plants with a multicolor marker set. Plant $J$ 59: 169-178.

GOMORD V, DENMAT L A, FITCHETTE-LAINE A C, SATIAT-JEUNEMAITRE B, HAWES C and FAYE L. (1997b). The C-terminal HDEL sequence is sufficient for retention of secretory proteins in the endoplasmic reticulum (ER) but promotes vacuolar targeting of proteins that escape the ER. Plant $J 11: 313-325$.

GREBENOKRJ, PIERSONE, LAMBERT GM, GONG F C, AFONSO CL, HALDEMANCAHILL R, CARRINGTON J C and GALBRAITH D W. (1997). Green-fluorescent protein fusions for efficient characterization of nuclear targeting. Plant J11:573-586.

GUNNING BES, SCHWARTZ OM (1999). Confocal microscopy of thylakoid autofluorescence in relation to origin of grana and phylogeny in the green algae. Functional Plant Biol. 26: 695-708.

HASELOFF J, AMOS B (1995). GFP in plants. Trends Genet, 11: 328-329.

HASELOFFJ, SIEMERING KR, PRASHERDC, HODGE S (1997). Removal of a cryptic intron and subcellular localization of green fluorescent protein are required to mark transgenic Arabidopsis plants brightly. Proc Natl Aca. Sci USA, 94: 2122-2127.

HASELOFF J. (1999). GFP variants for multispectral imaging of living cells. Methods Cell Biol 58: 139-151

HEIM R, CUBITT AB, TSIEN RY (1995). Improved green fluorescence. Nature 373: 663-664

HELD M A, BOULAFLOUS A and BRANDIZZI F. (2008). Advances in fluorescent protein-based imaging for the analysis of plant endomembranes. Plant Physiol 147: 1469-1481.

ICHIARAA, TANAAMI T, ISOZAKI K, SUGIYAMA Y, KOSUGI Y, MIKKURIYA K, ABE M, UEMURA I (1996). High-speed confocal scanning microscopy using Nipkow scanner with micro lenses for a 3D imaging of fluorescent molecule in real time. Bioimages, 4: 57-62.

ITAYAA, LIANG G, WOO YM, NELSON RS, DING B (2000). Nonspecific intercellular protein trafficking probed by green fluorescent protein in plants. Protoplasma, 213: $165-175$.

JACH G. (2006). Use of fluorescent proteins as reporters. Methods Mol Biol 323: 275-291.

KARIMI M, DEPICKER A and HILSON P. (2007). Recombinational cloning with plant gateway vectors. Plant Physiol 145: 1144-1154.

KATO N, REYNOLDS D, BROWN M, BOISDORE M, FUJIKAWA Y, MORALES A AND MEISEL L (2008) Multidimensional fluorescence microscopy of multiple organelles in Arabidopsis seedlings. Plant Methods 4, 9.

KŘEČEKP, SKŮPAP, LIBUS J, NARAMOTOS, TEJOSR, FRIMLJANDZAŽÍIMALOVÁ E (2009). The PIN-FORMED (PIN) protein family of auxin transporters. Genome Biol. 10: 249

LAPLAZE L, PARIZOTB, BAKERA, RICAUD L, MARTINIEREA, AUGUYF, FRANCHE C, NUSSAUME L, BOGUSZ D and HASELOFF J. (2005). GAL4-GFP enhancer trap lines for genetic manipulation of lateral root development in Arabidopsis thaliana. J Exp Bot 56: 2433-2442.

LEMONICKMD (1986). Of fireflies and tobacco plants. TIMEMagazine, Vol. 128 No. 20.

LIPPINCOTT-SCHWARTZ J and PATTERSON G H. (2009). Photoactivatable fluorescent proteins for diffraction-limited and super-resolution imaging. Trends Cell Biol 19: 555-565.

MAGLIERY T J, WILSON C G, PAN W, MISHLER D, GHOSH I, HAMILTON A D and REGAN L. (2005). Detecting protein-protein interactions with a green fluorescent protein fragment reassembly trap: scope and mechanism. J Am Chem Soc 127: 146-157.

MAIZELA, VONWANGENHEIMD, FEDERICIF, HASELOFFJ, STELZEREH. (2011). High resolution, live imaging of plant growth in near physiological bright conditions using light sheet fluorescence microscopy. Plant J. 68: 377-385.

MATZ MV, FRADKOV AF, LABAS YA, SAVITSKY AP, ZARAISKY AG, MARKELOV ML, LUKYANOV SA (1999). Fluorescent proteins from nonbioluminescent Anthozoaspecies. Nat. Biotechnol 17: 969-973.

MILLWOOD RJ, MOON HS, STEWART CN (2008). Fluorescent proteins in transgenic plants. In Reviews in Fluorescence 2008 (Ed. CD Geddes). Springer, New York, pp. 387-403. DOI 10.1007/978-1-4419-1260-2_16

MISHIN AS, SUBACH FV, YAMPOLSKY IV, KING W, LUKYANOV KA, VERKHUSHA VV (2008). The first mutant of the Aequorea victoria green fluorescent protein that forms a red chromophore. Biochem. 47: 4666-4673.

MORENO-RISUENO M A, BUSCH W and BENFEY P N. (2010). Omics meet networks - using systems approaches to infer regulatory networks in plants. Curr Opin Plant Biol 13: 126-131.

MORISE H, SHIMOMURA O, JOHNSON F, WINANT J (1974). Intermolecular energy transfer in the bioluminescent system of Aequorea. Biochemistry 13: 2656-2662.

MULLER J and JOHNSSON N. (2008). Split-ubiquitin and the split-protein sensors: chessman for the endgame. Chembiochem 9: 2029-2038.

NAGAI T, IBATA K, PARK ES, KUBOTA M, MIKOSHIBA K and MIYAWAKI A. (2002) $A$ variant of yellow fluorescent protein with fast and efficient maturation for cellbiological applications. Nat Biotechnol 20: 87-90.

NAKAJIMA, K., SENA, G., NAWY, T. and BENFEY, P.N. (2001). Intercellular movement of the putative transcription factor SHR in root patterning. Nature 413: 307-311.

NELSON B K, CAI X and NEBENFUHR A. (2007). A multicolored set of in vivo organelle markers for co-localization studies in Arabidopsis and other plants. Plant J 51: 1126-1136.

NGUYENAW AND DAUGHERTYPS (2005). Evolutionary optimization of fluorescent proteins for intracellular FRET. Nat. Biotechnol, 23: 355-360.

NIEDZ RP, SUSSMAN MR, SATERLEE JS (1995). Green fluorescent protein: an in vivo reporter of plant gene expression. Plant Cell Rep 14: 403-406.

NYFELER B, MICHNICK S W and HAURI H P. (2005). Capturing protein interactions in the secretory pathway of living cells. Proc Natl Acad Sci USA 102: 6350-6355.

ODELL JT, NAGY F and CHUANH. (1985). Identification of DNA sequences required for activity of the cauliflower mosaic virus 35S promoter. Nature 313: 810-812.

OKUMOTO S, JONES A and FROMMER WB. (2012). Quantitative imaging with fluorescent biosensors. Annu Rev Plant Biol 63: 663-706.

OSTERRIEDER A, CARVALHO C M, LATIJNHOUWERS M, JOHANSEN J N STUBBS C, BOTCHWAY S and HAWES C. (2009). Fluorescence lifetime imaging of interactions between Golgi tethering factors and small GTPases in plants. Traffic 10: 1034-1046.

OW DW, WOOD KV DeLUCA M, DE WET JR, HELINSKI DR, HOWELL SH (1986). Transient and stable expression of the firefly luciferase gene in plant cells and transgenic plants. Science 234: 856-859.

PAWLEY JB (1995). Handbook of Biological Confocal Microscopy. New York: Springer.

PERIASAMY A, SKOGLUND P, NOAKES C and KELLER R. (1999). An evaluation of two-photon excitation versus confocal and digital deconvolution fluorescence microscopy imaging in Xenopus morphogenesis. Microsc Res Tech 47: 172-181.

PETERSSONSV, JOHANSSONAI, KOWALCZYKM, MAKOVEYCHUKA, WANG JY, MORITZ T, GREBE M, BENFEY PN, SANDBERG G and LJUNG K. (2009). An auxin gradient and maximum in the Arabidopsis root apex shown by high-resolution cell-specific analysis of IAA distribution and synthesis. The Plant Cell 21: 1659.

PORTER J R, STAINS C I, JESTER B W and GHOSH I. (2008). A general and rapid cell-free approach for the interrogation of protein-protein, protein-DNA, and protein-RNA interactions and their antagonists utilizing split-protein reporters. $J$ Am Chem Soc 130: 6488-6497.

POTTER S M, WANG C M, GARRITY P A and FRASER S E. (1996). Intravital imaging of green fluorescent protein using two-photon laser-scanning microscopy. Gene 173: 25-31.

PU L and BRADY S. (2010). Systems biology update: cell type-specific transcriptional regulatory networks. Plant Physiol 152: 411-419.

RASHOTTE AM, DELONG A and MUDAY GK. (2001). Genetic and chemical reductions in protein phosphatase activity alter auxin transport, gravity response, and lateral root growth. Plant Cell 13: 1683-1697.

RIZZO MA, SPRINGER GH, GRANADA B, PISTON, DW (2004). An improved cyan fluorescent protein variant useful for FRET. Nat Biotechnol 22: 445-449.

ROST FWD (1995). Fluorescence Microscopy. Cambridge, UK. Cambridge University Press.

RUBARTM. (2004). Two-photon microscopy of cells and tissue. Circ Res 95: 1154-1166.

SENA G, FRENTZ Z, BIRNBAUM KD, LEIBLER S. (2011). Quantitation of cellular dynamics in growing Arabidopsis roots with light sheet microscopy. PLoS One, 6: E21303. 
SHANER NC, CAMPBELL RE, STEINBACH PA, GIEPMANS BNG, PALMER AE, TSIEN RY (2004). Improved monomeric red, orange and yellow fluorescent proteins derived from Discosomasp. red fluorescent protein. Nat Biotechnol22: 1567-1572.

SHEEN J, HWANG SB, NIWA Y, KOBAYASHI H, GALBRAITH DW (1995). Green fluorescent protein as a new vital marker in plant cells. Plant J 8: 777-784.

SHIMOMURA O, JOHNSON F, SAIGA Y (1962). Extraction, purification and properties of aequorin, a bioluminescent protein from the luminous hydromedusan, Aequorea. J Cell Comp Physiol 59: 223-239.

SPARKES I A. (2010). Motoring around the plant cell: insights from plant myosins. Biochem Soc Trans 38: 833-838.

SWARUP R, KRAMER EM, PERRY P, KNOX K, LEYSER HM, HASELOFF J, BEEMSTER GT, BHALERAO R and BENNETT MJ. (2005). Root gravitropism requires lateral root cap and epidermal cells for transport and response to a mobile auxin signal. Nat Cell Biol 7: 1057-1065.

SWARUP R, WELLS DM and BENNETT M (2013). Root Gravitropism. Plant Roots: The Hidden Half. Chapter 19. 4th Edition, CRC Press. Amram Eshel \& Tom Beeckman (Eds.).

SWEDLOW J R and PLATANI M. (2002). Live cell imaging using wide-field microscopy and deconvolution. Cell Struct Funct 27: 335-341.

SWIFT SR, TRINKLE-MULCAHY L (2004). Basic principles of FRAP, FLIM, and FRET. Proc of the Roy Microsc Soc 39: 3-10.

TAN X, CALDERON-VILLALOBOS LI, SHARON M, ZHENG C, ROBINSON CV, ESTELLE M and ZHENG N. (2007). Mechanism of auxin perception by the TIR1 ubiquitin ligase. Nature 446: 640-645.

THIMANN KV. (1935). On the plant growth hormone produced by Rhizopus suinus. Journal of Biological Chemistry 109: 279-291.

TIWARI SB, WANG XJ, HAGEN G and GUILFOYLE TJ. (2001). AUX/IAA proteins are active repressors, and their stability and activity are modulated by auxin. Plant Cell 13: 2809-2822.

TSIEN RY (1998). The green fluorescent protein. Annu Rev Biochem 67: 509-544.

TSUGEKI R and FEDOROFF N V. (1999). Genetic ablation of root cap cells in Arabidopsis. Proc Natl Acad Sci USA 96: 12941-12946.

ULMASOV T, MURFETT J, HAGEN G and GUILFOYLE T. (1997). Aux/IAA proteins repress expression of reporter genes containing natural and highly active synthetic auxin response elements. Plant Cell 9: 1963-1971.

VERNOUX T, BRUNOUD G, FARCOT E, MORIN V, VAN DEN DAELE H, LEGRAND
J, OLIVA M, DAS P, LARRIEU A, WELLS D et al., (2011). The auxin signalling network translates dynamic input into robust patterning at the shoot apex. Mol Syst Biol 7: 508.

WALLRABE H and PERIASAMY A. (2005). Imaging protein molecules using FRET and FLIM microscopy. Curr Opin Biotechnol 16: 19-27.

WANG E, BABBEY CM, DUNN KW (2005). Performance comparison between the high-speed Yokogawa spinning disk confocal system and single-point scanning confocal systems. J. Micros. 218: 148-159.

WANG L, JACKSON WC, STEINBACH PA, TSIEN RY (2004). Evolution of new nonantibody proteins via iterative somatic hypermutation. Proc Natl Acad Sci USA 101: 16745-16749.

WARD T H and BRANDIZZI F. (2004). Dynamics of proteins in Golgi membranes: comparisons between mammalian and plant cells highlighted by photobleaching techniques. Cell Mol Life Sci 61: 172-185.

WEINTHALD and TZFIRAT. (2009). Imaging protein-protein interactions in plant cells by bimolecular fluorescence complementation assay. Trends Plant Sci 14: 59-63.

WEIJERS D, FRANKE-VAN DIJK M, VENCKEN RJ, QUINT A, HOOYKAAS P and OFFRINGA R. (2001). An Arabidopsis Minute-like phenotype caused by a semi-dominant mutation in a RIBOSOMAL PROTEIN S5 gene. Development 128: 4289-4299.

WELLS DM, LAPLAZE L, BENNETT MJ and VERNOUX T. (2013). Biosensors for phytohormone quantification: challenges, solutions, and opportunities. Trends Plant Sci. 18: 244-249.

WOLVERTON C, PAYA AM and TOSKA J. (2011). Root cap angle and gravitropic response rate are uncoupled in the Arabidopsis pgm-1 mutant. Physiol Plant 141: 373-382.

YANG TT, CHENG LZ, KAIN SR (1996). Optimized codon usage and chromophore mutations provide enhanced sensitivity with the green fluorescent protein. Nucleic Acid Res 24: 4592-4593.

ZACHARIAS DA, VIOLIN JD, NEWTON AC, TSIEN RY (2002). Partitioning of lipidmodified monomeric GFPs into membrane microdomains of live cells. Science 296: 913-916.

ZAMYATNINAA, JR., SOLOVYEV A G, BOZHKOV P V, VALKONEN J P, MOROZOV $S Y$ and SAVENKOV E I. (2006). Assessment of the integral membrane protein topology in living cells. Plant $J$ 46: 145-154.

ZHOU R, BENAVENTE LM, STEPANOVA, AN and ALONSO, JM (2011). A recombineering-based gene tagging system for Arabidopsis. Plant J 66: 712-723. 


\section{Further Related Reading, published previously in the Int. J. Dev. Biol.}

Lessons from a search for leaf mutants in Arabidopsis thaliana

José Manuel Pérez-Pérez, Héctor Candela, Pedro Robles, Víctor Quesada, María Rosa Ponce and José Luis Micol

Int. J. Dev. Biol. (2009) 53: 1623-1634

Arabidopsis monomeric G-proteins, markers of early and late events in cell differentiation

Mariette Bedhomme, Chantal Mathieu, Amada Pulido, Yves Henry and Catherine Bergounioux

Int. J. Dev. Biol. (2009) 53: 177-185

The role of ion fluxes in polarized cell growth and morphogenesis: the pollen tube as an experimental paradigm

Erwan Michard, Filipa Alves and José A. Feijó

Int. J. Dev. Biol. (2009) 53: 1609-1622

Epidermal differentiation: trichomes in Arabidopsis as a model system

Swen Schellmann and Martin Hülskamp

Int. J. Dev. Biol. (2005) 49: 579-584

Young microspore-derived maize embryos show two domains with defined features also present in zygotic embryogenesis.

Pilar S Testillano, Carmen Ramírez, Jezabel Domenech, Maria-José Coronado, Phillipe Vergne, Elisabeth Matthys-Rochon and María C Risueño

Int. J. Dev. Biol. (2002) 46: 1035-1047

5 yr ISI Impact Factor $(2011)=2.959$
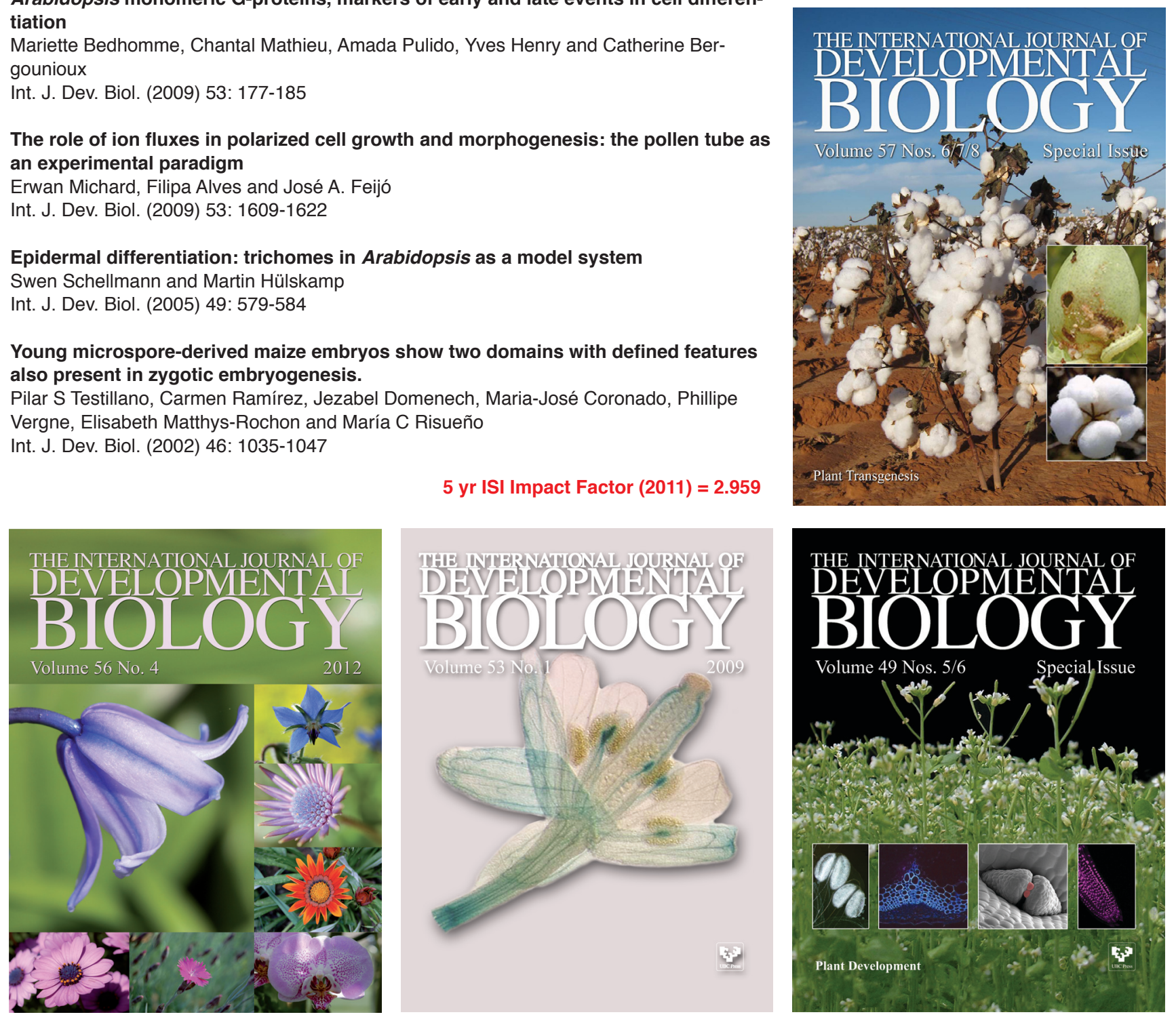